\title{
Objetividade ética e a morte da ontologia em Putnam
}

\author{
Ethical objectivity and the death of ontology in Putnam
}

\section{Luca Nogueira Igansi ${ }^{*}$}

\begin{abstract}
Resumo: Rastrearemos a refutação da necessidade de fundamentos ontológicos para teorias éticas de Putnam analisando sua trajetória por autores como Quine, Moore e Wittgenstein. Partiremos do naturalismo epistemológico de Quine para estabelecer sua base coerentista pragmática. Então, investigaremos seu distanciamento da ontologia conforme sua perspectiva wittgensteiniana do conceitualismo mooreano e platônico. Caracterizando Heidegger como alvo primário de sua crítica a uma necessidade de ontologia, afasta-se mesmo de Quine ao abraçar uma relatividade conceitual inspirada na mereologia e em jogos de linguagem para estabelecer a objetividade da ética sem a necessidade de objetos. Por fim, a partir dessa definição, investigaremos a concepção de ética segundo Putnam, fortemente inspirada em Dewey e Aristóteles em diálogo com Levinas e Kant em prol de um "florescimento cognitivo humano". Sua definição é breve e superficial, todavia clama que tais características sejam necessárias a fim de dar maleabilidade à ética, em contraponto a uma definição rígida e facilmente quebradiça tendo em vista o amplo descordo presente na filosofia moral. Esta flexibilidade não cairia em relativismo absoluto uma vez que preza a razoabilidade e progresso, assim como evitaria doutrinas danosas "anti-florescimento".
\end{abstract}

Palavras-chave: Ética. Objetividade. Ontologia. Relativismo conceitual.

\begin{abstract}
We will trace Putnam's rebuttal of the necessity of ontological foundations for ethical theories, analyzing his trajectory through authors such as Quine, Moore, and Wittgenstein. From Quine's epistemological naturalism, we will establish his coherentist pragmatism perspective. From there, we'll investigate his departure from ontology according to his Wittgensteinian perspective of Moorean and Platonic conceptualism. Characterizing Heidegger as the primary target of bis criticism of a necessity for ontology, he dissociates himself even from Quine by embracing a conceptual relativity inspired in mereology and language-games to establish the objectivity of ethics without a requirement for objects. Lastly, from this definition, we will investigate Putnam's conception of ethics, which is strongly inspired by Dewey and Aristotle in dialogue with Levinas and Kant toward a "buman cognitive flourishing." His definition is brief and superficial, however, he claims such characteristics are necessary toward malleability in ethics, contrasting with a rigid definition which can
\end{abstract}

* Universidade Federal de Pelotas - Pelotas, RS, Brasil. Doutorando em epistemologia moral, Programa de Pós-Graduação em Filosofia na UFPel. E-mail: luca.igansi@gmail.com. 
be easily broken given the ample disagreement in moral philosophy. This flexibility would not fall into absolute relativism for it praises reasonability and progress, likewise avoiding damaging "anti-flourishing" doctrines.

Keywords: Ethics. Objectivity. Ontology. Conceptual relativism.

Data de recebimento: $24 / 09 / 2020$

Data de aceite: $05 / 11 / 2020$

DOI: $10.23925 / 2316-5278.2020 v 21 i 2 p 246-259$

\section{Introdução}

Hilary Putnam, um dos filósofos mais relevantes do último século, caracteriza-se por uma miríade de propostas que permeiam diversas áreas do conhecimento. Em constante autocrítica, passou por mudanças constantes de posicionamento durante sua vida. (NAVIA, 2016, p. 133-134). Célebre discípulo de Quine, trabalhou também a naturalização da epistemologia e da relação entre conhecimento, ética e ciência.

Neste trabalho, pretendo focar na abordagem de Putnam acerca do que ele denomina como a "morte" da ontologia, e como ele busca salvaguardar a objetividade frente a este desafio tanto no discurso científico, lógico e matemático quanto no discurso ético. Iniciarei apresentando a naturalização epistemológica de Quine como uma base para o entendimento da teoria de Putnam na segunda seção, oferecendo um panorama de sua definição, e algumas críticas e reformulações breves de comentadores. Na terceira seção, ilustrarei alguns personagens comuns nas obras que tratarei, a saber, Ethics without ontology (2005) e Reason, truth and history (1981). Isto servirá de base para entendermos o posicionamento pressuposto de Putnam, fortemente atrelado à Wittgenstein, e o que ele busca criticar, representado por Moore.

Na quarta seção, adentrarei em descrever a tarefa de Putnam de definir e posteriormente eliminar a noção de ontologia do discurso como um todo, e como ainda assim procura defender uma noção de objetividade coerente. Por fim, na quinta seção, trabalharei a noção de ética no pensamento de Putnam e como ela se relaciona à sua refutação da ontologia e consegue se adequar à sua concepção de objetividade, versando sobre sua refutação da dicotomia entre fato e valor.

\section{A naturalização epistemológica de Quine}

Putnam segue parte do caminho de seu mentor ao tentar trabalhar a relação entre epistemologia e ciência. Quine estava preocupado em retirar a epistemologia de seu status fundacionalista em uma filosofia primeira, "[t]he old tendency [...] to base science on something firmer and prior in the subject's experience" (QUINE, 1969, p. 87) para um coerentismo naturalizado com as ciências. Embora Quine não seja o foco de nosso trabalho, nos é interessante entender um pouco de sua perspectiva a fim de clarificar a base da qual Putnam parte e, de certa forma, contrasta-se. 
A filosofia primeira na perspectiva quineana é rastreável ao cogito cartesiano (KIM, 1988, p. 381-383), no qual busca-se fundamentar todo o conhecimento (crenças verdadeiras justificadas) em axiomas basilares que garantem a veracidade de proposições mais complexas sobre o mundo - uma perspectiva mentalista que foi herdada pelos empiristas e positivistas posteriores (KIM, 1988, p. 384).

Como Paul A. Gregory (2008) coloca, essa perspectiva euclidiana de justificar conclusões e premissas a partir de axiomas fundacionais torna-se, semelhante às críticas a Quine (como as do próprio Kim, as quais não me adentrarei), cíclica. Quine procura superar esta relação justificacional (lógica), baseada em uma epistemologia normativa, com uma relação causal-nomológica, baseada em uma psicologia cognitiva - ou seja, com um viés descritivo do processo de aquisição de crenças (KIM, 1988, p. 388).

Isto leva à uma inversão da perspectiva clássica de conhecimento: uma vez que nossas representações (output) são torrencialmente mais complexas que nossa experiência do mundo (input), que é limitada, (KIM, 1988, p. 389-390; QUINE, 1969, p. 82-83) temos uma relação horizontal entre nossa teoria de mundo a priori (lógicomatemática), as teorias científicas, as leis da natureza e nossa experiência empírica. Há, portanto, um equilíbrio reflexivo entre teoria e experiência, uma via de duas mãos entre ambos onde ambos adequam-se conforme o necessário. Portanto,

[t]here is thus reciprocal containment, though containment in different senses: epistemology in natural science and natural science in epistemology. [...] We are after an understanding of science as an institution or process in the world, and we do not intend that understanding to be any better than the science which is its object. (QUINE, 1969, p. 83-84).

Assim, nossa interação com o mundo não parte de uma tabula rasa que constrói uma concepção de realidade a partir de diversas experiências específicas; mas sim, nossa cultura, comunidade epistêmica e feitio fisiológico formam já um arcabouço cognitivo o qual nos permite experienciar o mundo em um espectro amplo, embora limitado, o que, por sua vez, nos convida a ajustar nossa teoria de acordo com esses estímulos e, assim, ad infinitum. Estamos inseridos em um contexto específico desde o nascimento e não há como tratar dele fora dele mesmo. Em um viés semelhante a Wittgenstein (comparação que nos será relevante para a próxima seção), Quine aponta que:

[t]he philosopher's task differs from the others', then, in detail; but in no such drastic way as those suppose who imagine for the philosopher a vantage point outside the conceptual scheme that he takes in charge. There is no such cosmic exile. (QUINE, 2013, p. 254).

Voltaremos brevemente a esta posição quineana quando tratarmos do problema ontológico que ela pressupõe. É suficiente clarificar no momento que Putnam abraça em grande parte esta perspectiva, mas com ressalvas que trataremos adiante. 


\section{Wittgenstein versus Moore}

Putnam versa por diversos autores ao trabalhar suas perspectivas, todavia, alguns poucos se destacam como mais frequentes através de suas obras. Em primeiro lugar, a figura mais constante é, sem dúvida, seu mentor Quine. Contudo, parte de sua relação intelectualmente conturbada com ele já foi sugerida anteriormente, e será investigada mais aprofundadamente nas seções seguintes. Assim, por mais que as "bases" do pensamento de Putnam sejam invariavelmente quineanas, associálos diretamente seria errôneo. Nesta seção, apresentarei os principais autores que Putnam trabalha a fim de esclarecer sua teoria para que tenhamos uma noção geral de seu posicionamento. Como o título da seção sugere, contrastaremos sua afinidade com Ludwig Wittgenstein e seu distanciamento com G. E. Moore para tais objetivos.

Putnam refere-se constantemente a Wittgenstein, sendo parte importante de seu pensamento como aponta Navia (2016, p. 134), especialmente nas Investigações filosóficas e em Da certeza. Em Ethics without ontology (2005), Putnam adota seu paradigma do uso de jogos-de-linguagem em um lebenswelt como papel central em sua tese (PUTNAM, 2005, p. 16, 22) e, especialmente na terceira conferência para esclarecer seu posicionamento acerca de "fundação" ontológica (2005, p. 5255, 62-63). Da mesma forma, em Reason, truth and history (PUTNAM, 1981) temos 53 instâncias de "Wittgenstein" em suas 222 páginas de texto - virtualmente uma ocorrência a cada quatro páginas, ainda mais se considerarmos que a grande maioria está presente até o quinto capítulo ( 47 instâncias até a página 124, configurando mais de uma ocorrência a cada três páginas). Alguns exemplos são uma referência direta às Investigações ao tratar da refutação da hipótese "fenomenológica" (conforme a definição wittgensteiniana) do cérebro na cuba (1981, p. 20-21) e ao tratar de sua perspectiva de "seguir uma regra" (1981, p. 66-69).

Embora nos aprofundaremos na teoria ontológica e ética de Putnam apenas na próxima seção, cabe uma ilustração dos motivos de seu alinhamento intenso à Wittgenstein. O autor austríaco procura em suas Investigações filosóficas (WITTGENSTEIN, 2009) afastar-se da perspectiva agostiniana de linguagem, na qual através da ostensividade associa-se metafisicamente, dogmaticamente, um conceito à um objeto (2009, \$38, p. 23e). Embora ele

[...] does not disagree that the process of language learning has this strong ostensive aspect, $[\ldots]$ he attempts to escape a greater commitment to this strange connection between word and object. He does so by shifting this paradigm of meaning: it is given not by the object itself, but by our use of the words when we interact with it in some way. (IGANSI, 2019, p. 125).

Segundo Putnam, James Conant identifica corretamente que, apesar de discordar com a conexão entre jogos de linguagem e mundo que Sabina Loviband propõe, lhe agrada o viés realista, mesmo também concordando com a concepção acima e a colocação correta de Simon Blackburn que diferentes jogos de linguagem são, conforme o próprio Wittgenstein reitera, diferentes e que similaridades superficiais na forma linguística podem ter profundas diferenças de função. O 
pluralismo conceitual é como Putnam salvaguarda-se de um "platonismo" ontológico da linguagem em prol de uma objetividade discursiva, como veremos na seção 4.2.

Esta perspectiva contrasta diretamente com seu primeiro trabalho, o Tractatus logico-philosophicus (WITTGENSTEIN, 1922), em que ele havia abraçado o positivismo lógico atomista do início do século que ele mesmo identifica como problemático por atrelar-se à perspectiva agostiniana - que, por sua vez, é caracteristicamente platônica.

Platão é outro autor que Putnam frequentemente refere-se nas obras supracitadas. Invariavelmente, ao tratar de ontologia em Ethics without ontology, Platão é um dos principais representantes do que ele chama de metafísica inflamatória (PUTNAM, 2005, p. 17-18). Todavia, outro nome é atrelado ao de Platão ao tratar desta perspectiva: G. E. Moore. Acredito que nos será mais interessante focar neste segundo uma vez que Putnam parece intencionalmente posicionarse diametralmente oposto às concepções ontológicas e éticas presentes em seu Principia ethica (MOORE, 1993).

Moore delineia seu objetivo de forma bastante clara ao iniciar esta obra ao comparar seu intuito na ética como de Kant na metafísica:

I have endeavoured to write 'Prolegomena to any future Ethics that can possibly pretend to be scientific.' I have endeavoured to discover what are the fundamental principles of ethical reasoning; and the establishment of these principles, rather than of any conclusions which may be attained by their use, may be regarded as my main object (MOORE, 1993, p. 35).

Esta temática, como vimos, é bastante cara aos epistemólogos do século XX, especialmente a Quine e Putnam. Todavia, como um estudo da cientificidade da ética pode ser relacionado à metafísica inflamatória de Platão? Acredito que esta relação ficará clara ao longo do artigo, mas uma breve análise da proposta mooreana nos será útil no momento.

Moore pretende uma tarefa metaética por excelência: identificar os sentidos do uso do termo "bom" que são relevantes à ética, nominalmente, do sentido de bom enquanto aquilo que possui valor intrínseco (MOORE, 1993, p. 68).

Assim ele busca identificar dois aspectos principais de sentenças normativas, ou seja, referenciais a normas e regras de cunho moral: que (i) possuem apofanticidade insulada, ou seja, cada caso é específico e independe de provas (aspecto não-moral), e (ii), a evidência para o dever moral (moral ought) é intuitiva, ou seja, auto-evidente, assim como causal quanto à ação em questão - o que também implica sua objetividade. (IGANSI, 2014, p. 14).

Assim, temos um intuicionismo relativo à avaliação do juízo moral, em que há a necessidade da presença de bom (no sentido relevante à ética) em um estado-decasos enquanto operador apofântico. Ou seja, este bom consta como objeto simples (não-natural num sentido platônico), e identificá-lo em um juízo analítico seria um erro - o que torna-o indefinível, apesar de objetivo. A Ética, assim, teria autonomia à parte das outras ciências por seu caráter sui generis. 
Putnam relaciona esses estados de casos hipotéticos com as formas puras suprassensíveis platônicas perse (PUTNAM, 2005, p. 17-18), em um comprometimento ontológico semelhante ao que Wittgenstein identifica no atomismo lógico. Além do mais, o autor americano se distanciará desta dicotomia mooreana entre proposições valorativas e as descrições factuais, aproximando o discurso científico e ético em oposição à Moore. Veremos mais adiante.

\section{Matando a ontologia para salvar a objetividade}

\subsection{Definindo ontologia}

Putnam inicia Ethics without ontology (2005) correlacionando seu intento com o de Heidegger ao criticar a ontologia tradicional com um foco no lebenswelt wittgensteiniano em um viés pró-falibilista e anti-ceticista a fim de defender seu pluralismo pragmatista. Todavia, destoa-se de Heidegger em que este último não teria apresentado um entendimento "analítico" de ontologia (2005, p. 15-17). Putnam não pretende oferecer uma ontologia melhorada para superar a tradicional, mas sim, demonstrar que uma concepção ontológica é desnecessária - e quiçá danosa - para o empreendimento filosófico e, mais especificamente, ético.

Mas o que é a ontologia tradicional? Segundo Putnam, trataria da "ciência do Ser" na metafísica (2005, p. 17). A partir desta concepção, delineia dois tipos de ontologias principais: as inflamatórias e as deflacionárias. As ontologias inflamatórias seriam caracterizadas por um monismo na esfera ética por reduzir todos seus aspectos (fenômenos, problemas etc.) a um único critério imutável e invariável. Como mencionamos anteriormente, Putnam aponta para Platão e para G. E. Moore como exemplos dessa perspectiva por compartilharem o critério intuitivo para o acesso suprassensível daquilo que é "bom", tanto como "forma pura" em Platão como o objeto simples indefinível além dos estados de casos a que Moore se refere (PUTNAM, 2005, p. 17-18).

Em termos de objetividade, ambos os autores inflamatórios compreendem-na pressupondo uma conexão entre objetos do mundo e suas descrições - ou seja, a linguagem. Portanto, todas as asserções pretendem descrever a realidade (PUTNAM, 2005, p. 51-52). Na lógica, isto se traduz ao pensar relacionamentos lógicos (como tautologias) como se de fato estabelecesse relações entre "objetos intangíveis".

Quine, apesar de procurar subverter a tradição, baseia o conhecimento epistemológico em relações de clarificação conceitual de significado através da teoria dos conjuntos (em oposição à agenda positivista com foco na lógica) (QUINE, 1969, p. 69-71). Como identifica Putnam (2005, p. 78-81), Quine opta por abraçar uma espécie de platonismo da maneira que falamos de números na teoria dos conjuntos, pois são tomados como postulados - algo que Putnam vê como desnecessário (PUTNAM, 2005, p. 57).

Ontologias deflacionárias, por outro lado, afirmam que proposições ontológicas são "nada além de x" - em que "x" representa ou (i) "entidades míticas" do idealismo eliminacionista de Berkeley, assim como os nominalistas, ou (ii) palavras alternativas para uma ontologia mínima materialista, como a de Demócrito. Ambas versam sobre nossos equívocos conceituais frente à suas concepções ontológicas (PUTNAM, 2005, p. 19-22). 
Perante sua agenda de decretar o óbito da Ontologia, ambas concepções inflamatórias e deflacionárias estariam igualmente condenadas. A constante evolução conceitual e paradigmática que temos em nossas concepções de mundo condiz com nossos diferentes contextos teóricos de aquisição de conhecimento, e remetendo como vimos acima a Wittgenstein, uma variedade de jogos de linguagem é inerente às tentativas de múltiplas comunidades epistêmicas de entenderem o mundo. Aqui, as ontologias deflacionárias cairiam por terra. E estes jogos de linguagem permitem que dentro da própria linguagem se encontre sentido, colocando de lado também a necessidade do acesso ao suprassensível (PUTNAM, 2005, p. 21-22).

\subsection{Relatividade conceitual: ontologia para que?}

A partir dessa concepção wittgensteiniana de significado, Putnam desenvolve a ideia de "relatividade conceitual" como alternativa à necessidade ontológica de associar substância e existência em um sentido tradicional como em Husserl e Aristóteles (PUTNAM, 2005, p. 37-39). Tomando a segunda antinomia kantiana - a aparente contradição racional entre entender um ponto como espaço simples ou limitação de espaço -, Putnam traz a mereologia de Lezniewski, influenciado por Husserl (PUTNAM, 2005, p. 34-37). Tal posição utiliza-se da teoria dos conjuntos para denotar objetos: a união de quaisquer duas entidades ("coisas" quaisquer) denota um objeto. Um sapato e a Torre Eiffel poderiam ser um objeto: ambos compartilham lados esquerdos, parte superior e inferior, etc. Mas, apesar da inspiração por Husserl, Lezniewski afasta-se de uma necessidade substantiva para a existência de objetos - de fato, a existência dos objetos "em si" é irrelevante para seu status ontológico: o único critério que importa para tal é a convenção escolhida para a análise de entidades. Uma "coisa" pode ser definida como a soma de quaisquer outras duas "coisas" (PUTNAM, 2005, p. 36).

Putnam contrasta esse modelo mereológico com um modelo imaginário de Carnap em uma situação hipotética em um mundo em que há apenas três entidades indecomponíveis. Segundo o modelo imaginário carnapiano haveria, no total, três entidades neste mundo, mas para o modelo mereológico, haveria sete, dadas as diferentes somas possíveis entre as entidades. Aqui, a importância da concepção wittgensteiniana de significado torna-se clara: estes diferentes modelos pressupõem diferentes significados (jogos de linguagem), porém, esta diferença de significado não implica em uma diferença ontológica acerca do número de entidades. Tais modelos, então, agem como diferentes instruções para como lidarmos com objetos (PUTNAM, 2005, p. 41-42).

A relatividade conceitual, portanto, é caracterizada como uma antítese à antinomia kantiana, que pressupõe que "a mente não pode conhecer as coisas em si mesmas." Assim, define-se como "linguagens opcionais" para descrever objetos convencionalmente sem a necessidade de comprometimento ontológico - como David Lewis define, diferentes maneiras de se resolver problemas de coordenação, como em que lado da rua dirigir: convenções voláteis independentes de metafísica - "[...] as a choice between two specifiable ways of using words" (PUTNAM, 2005, p. 45, cf. p. 42-45). Desta maneira, não temos contradições, (além de prima facie) apenas diferentes convenções - mesmo quando se formaliza algum enunciado de identidade (PUTNAM, 2005, p. 45-47). 
A objetividade sem objetos torna-se tangível neste ponto. Seu "fundamento" wittgensteiniano torna-se mais explícito no que o autor associa tal conceito à sua formulação em Da certeza, em que a fundação das paredes da casa - no caso, da validade da objetividade - parecem estar suportadas pela casa como um todo (PUTNAM, 2005, p. 62-63) - ou seja, em uma concepção hegeliana/pragmatista da interpretação como critério para a verdade conceitual na qual enunciados lógicos seriam capazes de descrever o mundo de alguma maneira a partir de maneiras metodológicas (e não psicológicas) de entender o mundo de tal forma que sua negação seja sem sentido (PUTNAM, 2005, p. 60-62). O equilíbrio reflexivo estaria garantido aqui entre os recursos conceituais e a capacidade de descrever o mundo - processo que pressupõe conhecimento de metodologia lógica da justificação, mas sem a necessidade de entidades "não-naturais" para verificar tais verdades ou métodos (PUTNAM, 2005, p. 62-65).

Mesmo na matemática, quando tratamos de provabilidade, não há uma relação coextensiva com verdade. Tentativas de identificar verdades matemáticas com provabilidade ignora o papel da matemática na física, e como verdades lógicas, aprendemos verdades matemáticas ao aplicar e aprender práticas e padrões da matemática em si mesma. A superioridade de uma objetividade sobre a necessidade de objetos na matemática vem de uma linha fregeana reinterpretada por Kreisel, em que (i) não há relação clara entre "objetos" matemáticos (relatividade conceitual) e (ii) existência é correlacionada com possibilidade, apenas (PUTNAM, 2005, p. 65-67). E assim, "nothing supports taking mathematical theorems as descriptions of a special realm of "abstract entities," and nothing is gained, in philosophy of mathematics or elsewhere, by so doing" (PUTNAM, 2005, p. 67).

Nesta seção pretendi desenvolver o argumento de Putnam para defender a objetividade do discurso sem um comprometimento com uma teoria ontológica. Uma vez que podemos ter uma multiplicidade de jogos de linguagem em equilíbrio reflexivo com critérios epistêmicos que ofereçam melhores maneiras de compreender o mundo sem a necessidade de um platonismo operante, tais critérios tornamse uma das ferramentas mais importantes para a manutenção da objetividade do discurso. Se obtive sucesso, as maneiras como deliberamos sobre a escolha destes critérios e sua relação com a valoração ética, segundo Putnam, deverão tornar-se evidentes na próxima seção.

\section{Fatos e valores}

Como se dá uma análise ética sem entidades suprassensíveis de verificação? O relativismo conceitual gera um relativismo moral absoluto? Há espaço para a ética em uma objetividade sem objetos? Pretendo trabalhar a teoria ética de Putnam nesta seção de maneira a responder estas questões, ou no mínimo apontar para que direção o autor lida com elas.

Após a definição acima do relativismo conceitual segundo Putnam, é possível prosseguir para entender sua formulação acerca da ética. Suas pretensões nesta área não são menos ambiciosas que na questão da objetividade e sua relação com a ontologia, apesar de partir de concepções mais simples.

Iniciarei com um delineamento de "ética" conforme Putnam, para então trabalhar seu papel em seu paradigma geral teórico. 


\subsection{Definindo "Ética"}

Putnam procura entender sistemas éticos como sistemas de preocupações interrelacionadas mutualmente apoiadas e parcialmente tensionadas, como os das grandes religiões (cristianismo, budismo, judaísmo etc.) Isto entra em contraste com perspectivas como (i) a "regra de ouro" e seu "filho", o imperativo categórico, (ii) análises das raízes "sociobiológicas" da ética e (iii) a perspectiva nietzscheana, que entra em contraste com sua definição principal. Para representar sua própria concepção de teoria ética, Putnam afirma invocar três autores principais, porém invoca quatro: em ordem cardinal, Emmanuel Levinas, Immanuel Kant e Aristóteles, e fora de ordem, John Dewey (PUTNAM, 2005, p. 22-23).

Sua explicação é breve e deliberadamente superficial, então, não nos delongaremos aqui também. Apesar de citar todos estes nomes e priorizar Levinas e Kant, sem dúvida os mais significantes para sua teoria são Aristóteles e Dewey, como veremos adiante.

Levinas é primário, segundo Putnam, por sua irredutibilidade pragmática da ética, em que há uma obrigação incondicional direcionada ao sofrimento dos outros. Em segundo lugar temos Kant e sua universalizabilidade, que aplicado com Levinas, leva a preocupação com os outros para um âmbito geral. ${ }^{1}$ Aristóteles, por "fim", traria a noção de eudaimonia, ou "florescimento", em que haveria um foco na optimização das diversas maneiras diferentes de se viver "em mente e espírito" preocupando-se com seu auto-melhoramento (PUTNAM, 2005, p. 23-26). Uma aparente contradição, ou tensão, entre todos eles daria lugar a um apoio mútuo: a preocupação legítima com o outro de Levinas daria conteúdo para a formalidade kantiana em um contexto de florescimento aristotélico (PUTNAM, 2005, p. 26-28). John Dewey entra no foco que Putnam dá à ética em concentrar-se em problemas práticos, casos específicos ao invés de abstratos e na "bagunça" inerente da tarefa moral (PUTNAM, 2005, p. 28-32). Segundo o autor, a inexatidão falibilista inerente da controvérsia moral, que surge ao defender "recomendações gerais" éticas para pessoas reais em problemas contextualizados ao invés de leis normativas precisas para pessoas ideais, não gera uma falta de verdade moral - apenas uma falta de verdade platônica. Desenvolveremos este tópico do desacordo moral na próxima seção.

Embora uma formulação breve e superficial defende que a ética não deve ser uma "estátua nobre" com preocupações formais ou utilitaristas, mas sim uma "mesa bamba com muitas pernas"; uma construção simplificada, e que apesar de instável não é suscetível a ser facilmente derrubada (PUTNAM, 2005, p. 28).

\subsection{A inerência valorativa do discurso}

Conforme vimos na seção 4.2, o entendimento do relativismo conceitual como critério para objetividade desconexa de teorias ontológicas quaisquer leva a uma necessidade da manutenção da metodologia que o mantém. Mas que critérios seriam estes, e como se relacionariam com teorias éticas?

Primeiramente, o que seriam então juízos éticos? É difícil definir um jargão preciso de discurso ético, uma vez que termos considerados morais podem ser

1 Embora, como o prof. Dr. Ricardo Navia apontou em debates em sala de aula, tais fatores já estivessem presentes nas "grandes religiões" que citou anteriormente. 
utilizados em contextos não-morais e vice-versa. Putnam, inclusive, sugere uma espécie de cegueira em tentar defini-los estaticamente desta maneira. Assim, como há uma multitude de tipos de juízos éticos, temos uma sobreposição entre aqueles que pretendem descrever e aqueles que pretendem valorar (PUTNAM, 1981, p. 72-75).

Assim, ao tomarmos juízos de valor de razoabilidade e irrazoabilidade na ética, como os que envolvem termos de como "cruel" ou "simpático", e juízos de valor da ciência como "plausível", formulações "feias" e "coerência," temos aqui não uma série de descrições neutras mas sim avaliações carregadas de valor. Logicamente falando, são inferências não-dedutivas comuns e importantes tanto para as ciências naturais como para a resolução de problemas do cotidiano. Esta perspectiva é ausente de platonismo pois consiste de um exercício sobre raciocínios, não dependentes de uma concepção ontológica de "Razão" mas sim de uma noção de razoabilidade como compatível com preocupações para a vida ética (PUTNAM, 2005, p. 67-85).

Desta maneira,

[i]f ethical statements are, as I urge, forms of reflection that are as fully governed by norms of truth and validity as any other form of cognitive activity, the reason is that reflection on how it is reasonable to act given the overall concerns of the ethical life $[\ldots]$ is subject to the same standards of fallibilistic inquiry that all practical reasoning is subject to, and the notions of truth and validity are internal to practical reasoning itself (PUTNAM, 2005, p. 72).

Nesta passagem consta, resumidamente, a estrutura por detrás da crítica de Putnam à dicotomia entre fato e valor. Uma dicotomia institucionalizada, comum até fora da academia, mas cujo contraste é impreciso na melhor das hipóteses, pois mesmo seus defensores admitem que há valoração no discurso científico que, por exemplo, busca a verdade - apenas que essa valoração não é ética (PUTNAM, 1981, p. 127-128). Todavia, uma vez que a noção platônica cai por terra como critério de verdade, a própria noção de "verdade" necessita de averiguação convencional. Alguns apelam para o princípio da equivalência em Tarski, ignorando que é um princípio aplicado à verdade para criar um teorema a fim de asserir a verdade em uma metalinguagem, e não diz nada sobre os critérios racionais para entender a proposição a qual procura verificar - a verdade não é o ponto (PUTNAM, 1981, p. 128-130).

\subsubsection{0 problema do desacordo ético}

Dados os paralelos entre decisões éticas e práticas, há um problema inerente de desacordo como em quaisquer outras esferas práticas (como de política, religião etc.), e da mesma maneira, estão sujeitos a questionamentos sobre aplicabilidade, contexto e contra-argumentação. Estes questionamentos, muitas vezes, não possuem critérios fortes para uma previsão falibilista, e complicam a princípio um critério de regulação de objetividade (PUTNAM, 2005, p. 75-78).

Para ilustrar esta questão problemática, Putnam invoca o experimento de pensamento do "cérebro em uma cuba", que seria a radicalização do solipsismo existencialista característico da filosofia primeira em que se acreditaria que um 
"cientista maligno" (semelhante ao "gênio maligno" de Descartes) teria nos sujeitado a uma operação e nosso cérebro posto em uma cuba com os devidos cuidados para seu funcionamento contínuo. Através de um supercomputador avançadíssimo, controlarse-ia nossa percepção em uma realidade virtual a ponto de acreditarmos estarmos em um corpo em uma realidade (PUTNAM, 1981, p. 6-7). Sua refutação inicial a este posicionamento foge do escopo do presente trabalho, porém, ao aplicá-lo na questão do desacordo moral torna-se vital para nossa compreensão de sua proposta de superação (PUTNAM, 1981, p. 130-135). A diferença com sua formulação inicial consiste em que, ao invés de apenas uma pessoa acreditar nesta possibilidade como ocorrendo com ela naquele dado momento, é a população inteira da Austrália sob um "guru" que supostamente possui "acesso" ao conhecimento das intenções do cientista malévolo. Todavia, apesar disto, não possuímos nenhum desacordo científico nem ético com eles, dotados de uma concepção de mundo praticamente igual a nossa exceto pelo fato que veem tal como uma alucinação gerada pelo supercomputador.

Mesmo com todas as semelhanças e acordos possíveis, há um desacordo gritante em que enxergamos certa loucura ${ }^{2}$ (PUTNAM, 1981, p. 132) na perspectiva destes australianos. Loucura de fato, pois suas mentes teriam algum tipo de doença para pensarem de tal maneira. E como pensaríamos em tentar dialogar com eles acerca desta noção errônea? Primeiramente, podemos tentar nos aproximar com uma ideia de coerência, mas que eles julgam não ser importante. Depois, podemos oferecer o conceito da Navalha de Ockham, evitando a multiplicação desnecessária de entidades abstratas - porém, apesar de sua simplicidade funcional, dificilmente seria aceita por um povo que se sente feliz em criar cada vez mais objetos fora da cuba sem propósito algum para nossas experiências. Em terceiro, podemos tentar convencê-los do aspecto holístico do corpus íntegro, holístico da ciência, ao invés de aspectos separados.

Se algum destes passos poderia funcionar, continuará um mistério, mas o fato é que todo o parágrafo anterior consiste em como já partimos de uma noção de "florescimento cognitivo humano", ou seja, que nossa perspectiva de ciência é um sistema de vários valores. Isto não implica em um realismo metafísico, apenas que a mera ideia de reconhecer cognitivamente "[...] the 'real world' depends upon our values (and, again, vice versa)" (PUTNAM, 1981, p. 135). A ausência de conexão com uma ontologia e o subjugar dos enunciados éticos aos mesmos escrutínios de enunciados científicos permitem uma objetividade dos juízos éticos, mesmo que não se adeque a uma imagem de "fatos naturais" (PUTNAM, 2005, p. 77-78). O fato da perspectiva de Putnam aceitar perspectivas destoantes, e, por muitas vezes, incompatíveis de juízos éticos não implica que todos tais juízos possuam o mesmo valor de verdade. Veremos tal desenvolvimento mais aprofundadamente na próxima seção.

2 Putnam chega, com certa frequência, a tratar perspectivas dissidentes às suas como doenças mentais, tanto metaforicamente como vimos ao tratar de populações hipotéticas que defenderiam o paradigma do "cérebro na cuba" ou um "super-benthamismo" (PUTNAM, 1981, p. 139-141) como explicitamente ao fim da última conferência da primeira parte de Ethics without ontology (PUTNAM, 2005, p. 82-85) ao se referir às teorias de Paul Churchland, Bernard Williams e Simon Blackburn. Se esta é sua opinião pessoal ou está tentando demonstrar ao leitor a inseparabilidade entre fato e valor em sua asserção é uma questão em aberto. 


\subsubsection{Objetividade dos valores}

Esta concepção do discurso ético como uma ciência inexata condiz novamente com a perspectiva aristotélica; todavia, inexatidão não engendra subjetividade pura. Como vimos no exemplo do culto do cérebro na cuba, existem padrões, critérios para a aceitabilidade racional aplicados pelas comunidades epistêmicas, e o ato de procurar melhores concepções de racionalidade pressupõe uma concepção de "bom" - já que critérios cognitivos arbitrários iriam render os fatos como inúteis.

Assim, o domínio de conceitos e descritores para descrever pessoas e o cenário condizem com tais critérios de aceitabilidade racional, sujeitos à adequação em equilíbrio reflexivo em prol de descritores "bons" ou "ruins" (PUTNAM, 1981, p. 135-139).

Uma crítica comum a esta perspectiva é a de tomar a ética como muito subjetiva, em oposição a uma confiança de hiper-realismo da física - ao invés de reconhecer ambos como descrições racionalmente aceitáveis de contextos diferentes. Um subjetivismo não condiz com o viés público característico da comunidade epistêmica, que conforme Wittgenstein, compreende referências e conceitos como jogos de linguagem (PUTNAM, 1981, p. 143-145).

Bereft of the old realist idea of truth as 'correspondence' and of the positivist idea of justification as fixed by public 'criteria', we are left with the necessity of seeing our search for better conceptions of rationality as an intentional human activity, which, like every activity that rises above habit and the mere following of inclination or obsession, is guided by our idea of the good. (PUTNAM, 1981, p. 136-137).

A abordagem de Putnam, portanto, previne um relativismo completo dos juízos éticos uma vez que se cede uma maior objetividade de veracidade para aquelas concepções éticas que melhor dão conta do mundo em prol do florescimento. Da mesma forma, evita um absolutismo anti-histórico pois prevê a evolução conceitual e valorativa através da reavaliação e percepção de metas, como concorda Bernard Williams (NAVIA, 2016, p. 138-140). Os contínuos e inevitáveis padrões de aceitabilidade racional das comunidades epistêmicas pressupõe o distanciamento de um autoritarismo, pelas noções de razoabilidade e florescimento (PUTNAM, 1981, p. 147-149), assim como os casos extremos do nazismo, uma vez que a valoratividade cognitiva permite que rechacemos ideias factualmente errôneas e moralmente danosas - anti-eudaimônicas (NAVIA, 2016, p. 140-141).

\section{Considerações finais}

Procurei, neste trabalho, elucidar o contexto e o posicionamento de Putnam acerca da ontologia e sua inutilidade para o discurso científico, e, considerando sua refutação da existência da dicotomia entre fatos e valores, da mesma forma para o discurso ético.

Seu posicionamento é incomum e bastante singular. Putnam desenvolve sua teoria lidando com diversas críticas de todos os lados e procurando oferecer respostas adequadas em prol do progresso do debate. A mera noção de objetividade 
sem ontologia é algo que nem o próprio Quine foi capaz de aceitar, um fato curioso vindo de alguém que com as próprias mãos revolucionou o estudo da epistemologia, e mesmo a própria filosofia como um todo com seu naturalismo analítico. Não ao acaso que seu pupilo foi capaz de desenvolver teorias semelhantemente controversas e impactantes até para ele próprio.

Putnam oferece uma alternativa para a repetitiva história filosófica do conflito entre diversas concepções de verdade e bem moral que não dialogam entre si e muito menos aceitam a veracidade umas das outras. Seu relativismo conceitual consegue compactuar diferentes paradigmas de maneira a estimular o desenvolvimento de maneiras mais adequadas de tratar problemáticas filosóficas "florescendo" conceitos em contraste. Sua tentativa é quase "metafilosófica", em que ao invés trabalhar uma perspectiva metaética específica, versa sobre como ocorre o discurso como um todo e, como muitos destes pressupostamente neutros que utilizávamos, estavam imbuídos de conteúdo ético da mesma forma. É uma nova maneira de se pensar ética, metaética e filosofia em geral, estimulando um conflito construtivo de diferentes comunidades epistêmicas.

Evidentemente, seus posicionamentos não são ausentes de problemas. Suas concepções éticas podem ser consideradas demasiadamente simplificadas, e enquanto os aspectos matemático e lógico de seu texto são sempre devidamente extensamente tratados, as partes éticas acabam elas mesmas sobrepujadas pelas anteriores, ausentes de um desenvolvimento mais criterioso que faça jus à sua indivisibilidade valorativa do discurso descritivo. Mesmo que uma simplicidade metodológica seja estimada como virtuosa para um relativismo que não caia em absoluto caos epistêmico pelo próprio autor, o tema é tratado de maneira curta e merece maior atenção.

Ainda assim, são problemas relativamente superficiais e, estruturalmente, sua teoria possui traços únicos que levam diretamente ao questionamento do papel da filosofia e de sua metodologia em tempos contemporâneos. A naturalização da filosofia como apresentada por Quine, apesar de envolver o espírito filosófico tradicional de repensar a maneira como entendemos o mundo, convida - como em alguns clássicos como Aristóteles e Hume - a um diálogo constante com outras áreas do conhecimento a fim de um conhecimento pleno dos problemas filosóficos em questão. Desta maneira, é impensável que mantenhamos as mesmas estruturas metodológicas de eras anteriores, uma vez que a contemporaneidade nos traz ferramentas conceituais e tecnológicas que não apenas constantemente revolucionam teorias clássicas como também reinventam-se em uma velocidade surpreendente.

\section{Referências}

GREGORY, Paul A. Quine's naturalism: language, theory, and the knowing subject. London; New York: Continuum, 2008.

IGANSI, Luca N. A falácia naturalista na metaética contemporânea: usos e equívocos. Fundamento, v. 1, n. 8, p. 11-31, 2014. Disponível em: https://periodicos.ufop. br:8082/pp/index.php/fundamento/article/view/2353. Acesso em: 23 set. 2020.

IGANSI, Luca N. The concept of colour as a grammar problem in Wittgenstein. Revista PHILIA: Filosofia, Literatura \& Arte, Porto Alegre, v. 1, n. 1, p. 121-139, fev. 
2019. DOI: https://doi.org/10.22456/2596-0911.87079. Disponível em: https://seer. ufrgs.br/philia/article/view/87079. Acesso em: 23 set. 2020.

KIM, Jaegwon. What is "Naturalized Epistemology?". Philosophical Perspectives, v. 2, p. 381-405, 1988. DOI: https://doi.org/10.2307/2214082. Disponível em: https://www. jstor.org/stable/2214082?seq=1. Acesso em: 23 set. 2020.

MOORE, George E. Principia Ethica. 2. ed. London: Cambridge University Press, 1993.

NAVIA, Ricardo. In Memoriam Hilary Putnam (1926-2016): Problemáticas Decisivas

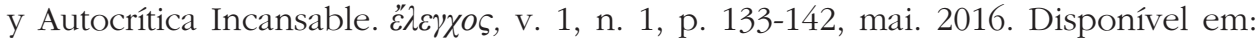
http://sfu.org.uy/ricardo-navia-hilary-putnam-in-memoriam-2/. Acesso em: 23 set. 2020 .

PUTNAM, Hilary. Ethics without ontology. Cambridge, MA: Harvard University Press, 2005.

PUTNAM, Hilary. Reason, truth, and history. Cambridgeshire; Cambridge: Cambridge University Press, 1981.

QUINE, Willard van O. Epistemology Naturalized. In: QUINE, Willard van O. Ontological relativity and other essays. New York: Columbia University Press, 1969. p. 69-91.

QUINE, Willard. van O. Word and object. Cambridge, MA: MIT Press, 2013.

WITTGENSTEIN, Ludwig. Philosophical investigations. Tradução de G. E. M. Anscombe; P. M. S. Hacker; Joachim Schulte. Oxford: Blackwell Publishing Ltd., 2009.

WITTGENSTEIN, Ludwig. Tractatus logico-philosophicus. Tradução de C. K. Ogden. London: Harcourt, Brace \& Company, Inc., 1922. 